Review

\title{
Organic micropollutants in wet and dry depositions in the Venice Lagoon
}

\author{
Andrea Gambaro ${ }^{\mathrm{a}, \mathrm{b}, *}$, Marta Radaelli ${ }^{\mathrm{b}}$, Rossano Piazza ${ }^{\mathrm{a}, \mathrm{b}}$, Angela Maria Stortini ${ }^{\mathrm{b}}$, Daniele Contini ${ }^{\mathrm{c}}$, \\ Franco Belosi ${ }^{\mathrm{d}}$, Roberta Zangrando ${ }^{\mathrm{a}}$, Paolo Cescon ${ }^{\mathrm{a}, \mathrm{b}}$ \\ ${ }^{a}$ University of Venice, Department of Environmental Science, Dorsoduro 2137, 30123 Venice, Italy \\ ${ }^{\mathrm{b}}$ Institute for the Dynamics of Environmental Processes (CNR-IDPA), Dorsoduro 2137, 30123 Venice, Italy \\ ${ }^{\mathrm{c}}$ Institute of Atmospheric Sciences and Climate (CNR-ISAC), Str. Lecce-Monteroni km 1.2, 73100 Lecce, Italy \\ dinstitute of Atmospheric Sciences and Climate (CNR-ISAC), Via Gobetti 101, 40129 Bologna, Italy
}

\section{A R T I C L E I N F O}

\section{Article history:}

Received 1 April 2009

Received in revised form 27 April 2009

Accepted 29 April 2009

Available online 12 June 2009

\section{Keywords:}

Organic micropollutants

Wet and dry deposition

Venice Lagoon

HRGC-HRMS

\begin{abstract}
A B S T R A C T
Atmospheric transport is an important route by which pollutants are conveyed from the continents to both coastal and open sea. The role of aerosol deposition in the transport of polycyclic aromatic hydrocarbons (PAHs), polychlorobiphenyls (PCBs) and polybromodiphenyls ethers (PBDEs) to water and soil systems has been evaluated by measuring their concentrations in wet and dry depositions to the Venice Lagoon. The organic micropollutant flux data indicate that they contribute to the total deposition flux in different ways through wet and dry deposition, showing that the prevalent contribution derives from wet deposition. The fluxes calculated for PBDEs, showed the prevalence of 47, 99, 100 and 183 congeners, both in dry and wet fluxes. With regard to PCBs, the flux of $\sum$ PCB for wet deposition is in the same order of magnitude of the diffusive flux at the air-water interface. The PAH fluxes obtained in the present study are similar to those obtained in previous studies on the atmospheric bulk deposition to the Venice Lagoon. The ratios between Phe/Ant and Fl/Py indicate that the pollutants sources are pyrolytic, deriving from combustion fuels.
\end{abstract}

\section{Contents}

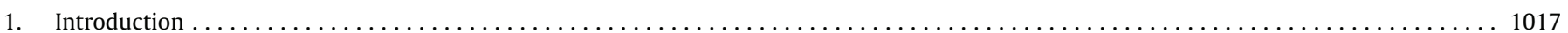

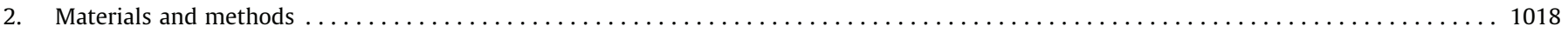

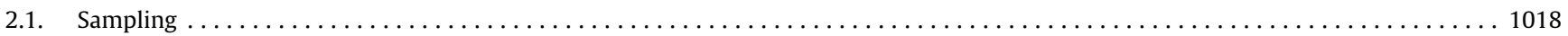

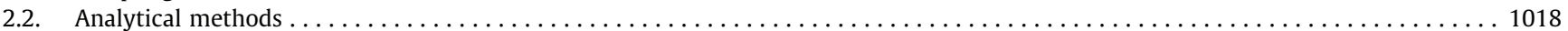

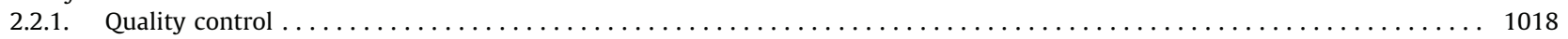

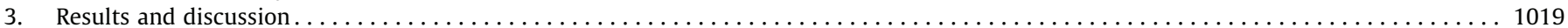

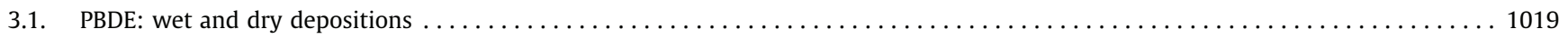

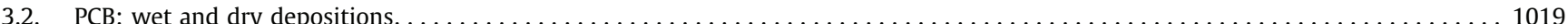

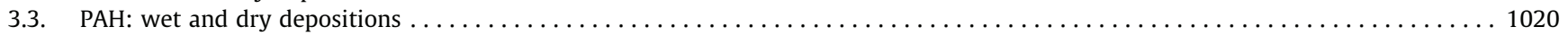

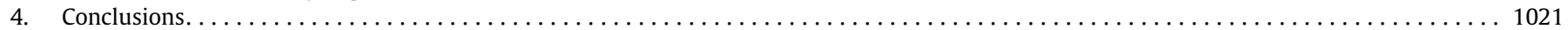

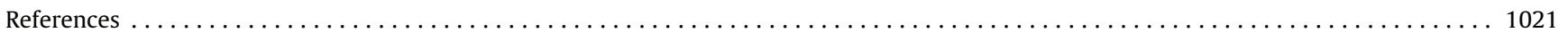

* Corresponding author. Address: University of Venice, Department of Environmental Science, Dorsoduro 2137, 30123 Venice, Italy. Tel.: +39 041 2348950; fax: +390412348549/2348628.

E-mail address: gambaro@unive.it (A. Gambaro).

\section{Introduction}

Atmospheric particles have an important role in the transport of various substances and pollutants through the various environment compartments, and their levels are controlled by both meteorological conditions and the physico-chemical characteristics of the particles themselves (Gambaro et al., 2005). 


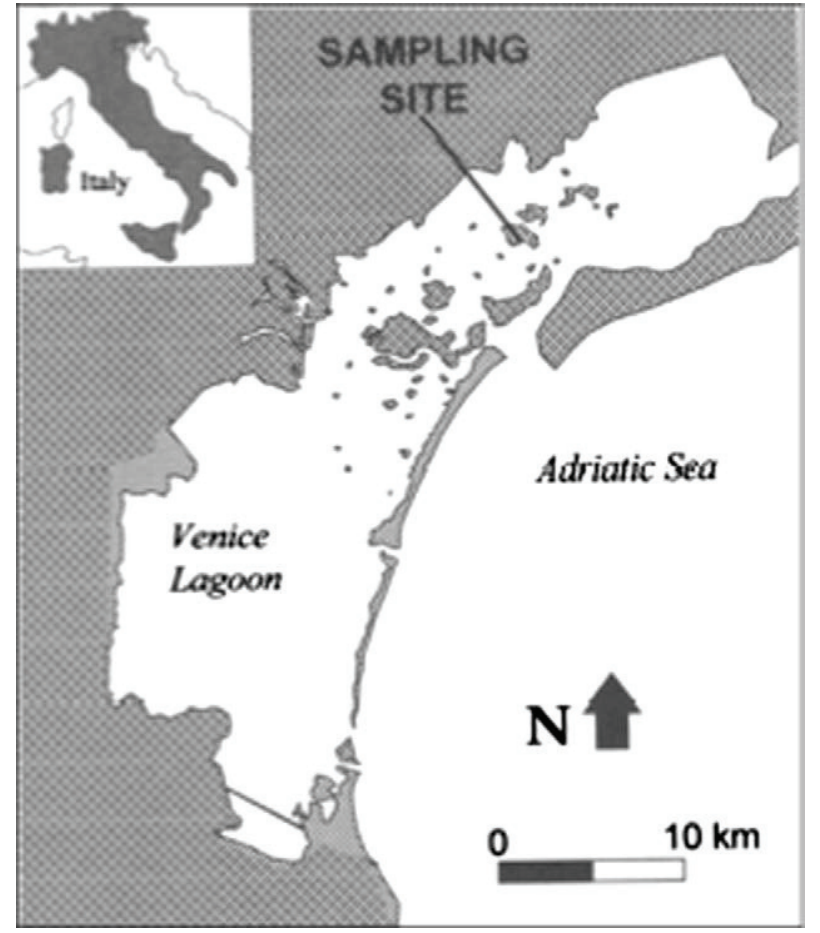

Fig. 1. Map showing the location of the sampling station.

The Venice Lagoon represents a complex environmental system. It is an example of an ecosystem that has been influenced by human interference for many years, in particular after World War II. The post-war period saw the growth of manufacturing activities in the nearby industrial district of Porto Marghera, where a number of plants are still present, engaged mainly in chlorine chemical processing, along with other major production cycles.

The Venice Lagoon is a superficial basin, along the northwest coast of the Adriatic Sea, with an area of $549 \mathrm{~km}^{2}$. It is connected to the sea through three entrances, enabling the exchange of over $50 \%$ of the whole volume of the lagoon in half a day. Water masses are an important sink and transport vector of pollutants, facilitating their interaction with other environmental compartments. Past studies have shown that the most significant processes in the contamination of this habitat are the direct emissions of industrial waste, the exchange of pollutants at the atmosphere-water (Manodori et al., 2006, 2007) and water-sediment interface, and, finally, the transfer of contaminants to rivers and lagoon waters.

In the light of the circumstances highlighted above, in recent years many scientific studies have attempted to estimate the importance of atmospheric aerosol on the Venice Lagoon, by considering the fluxes of pollutants caused by atmospheric depositions (Rossini et al., 2005) and the importance of air masses coming from different sources (Gambaro et al., 2004).

The present work attempts, for the first time to study the role of aerosol deposition in the transport of organic micropollutants in water and soil systems in the Venice Lagoon, by evaluating their concentrations in wet and dry depositions.

\section{Materials and methods}

\subsection{Sampling}

Sampling of wet and dry depositions, to evaluate their organic compounds concentration, was carried out between May and November 2005, with an average period of exposure of $36 \mathrm{~d}$.
The sampling site was located on Mazzorbetto Island, near Burano, in the northern part of the Venetian lagoon as shown in Fig. 1. The site was of interest because it is not a densely urbanised area and is not directly affected by industrial emissions sources.

The two sampling devices used to collect the wet and dry atmospheric depositions consisted of two vessels equipped with a rain sensor capable of triggering the cover, so as to protect the dry sample and collect the wet deposition in the other container. Organic micropollutants were collected in two stainless steel vessels (surface area $0.066 \mathrm{~m}^{2}$ ). The system used to collect the dry deposition consisted of a cylindrical support containing a layer of ultrapure water maintained at a constant level to simulate a natural deposition surface (Water Surrogate Surface) (Odabasi et al., 1999; Tasdemir et al., 2004). The stainless steel vessels became warm in the summer, causing the water and organic compounds to evaporate inside them. Therefore the temperature was controlled by a water flux refrigerated by a thermo cryostat, flowing inside an internal space of the sampler. In this way the water level and temperature inside the vessel remained constant throughout the sampling period.

\subsection{Analytical methods}

The organic micropollutants in the wet and dry deposition water samples were obtained by continuous liquid-liquid extraction, using a mixture of hexane-dichloromethane (1:1). The remaining particulate matter that had adhered to the surfaces of the sampler was collected by using filters to clean the sampler, this particulate matter was extracted using a mixture of pentanedichloromethane $(2: 1)$ in a closed flask using a sonic bath. After being united and mixed together, the extracts were dehydrated with anhydrous sodium sulphate, their volume was reduced to $5 \mathrm{~mL}$ under a nitrogen flow at $23{ }^{\circ} \mathrm{C}$ (Turbovap II Zimark) and they were cleaned using an automated multi-column system (PowerPrep, Fluid Management System Inc.). The samples were loaded onto a packed neutral silica column (flow: $2 \mathrm{~mL} \mathrm{~min}^{-1}$ ) previously conditioned with $50 \mathrm{~mL}$ of $n$-hexane (flow: $10 \mathrm{~mL} \mathrm{~min}^{-1}$ ). The PCBs, PAHs and PBDEs were eluted with $30 \mathrm{~mL}$ of $n$-hexane (flow: $10 \mathrm{~mL} \mathrm{~min}^{-1}$ ) followed by $30 \mathrm{~mL}$ of an $n$-hexane and dichloromethane mixture $\left(1: 1\right.$, flow: $\left.5 \mathrm{~mL} \mathrm{~min}^{-1}\right)$. The final volume was reduced to $500 \mu \mathrm{L}, 100 \mu \mathrm{L}$ of iso-octane was added and the volume reduced again to $100 \mu \mathrm{L}$. A MAT 95XP (Thermo Finnigan) high-resolution mass spectrometer, equipped with a Hewlett-Packard Model 5890 series II gas chromatograph, was used to analyze all the samples.

Before extraction seven carbon-13-labelled PBDEs (PBDE, 28, $47,99,100,118,153,183)$ and seven carbon-13-labelled PCBs (PCB 28, 52, 101, 138, 153, 180, 209) and one carbon-13-labelled IPA (Phenanthrene), were added to the water and filter extracts for use as internal standards in the quantification of the analytes in the samples.

Gas chromatographic separation was performed on a fused silica capillary column (J\&W Scientific DB-5MS, $60 \mathrm{~m} \times 0.25 \mathrm{~mm}$ O.D. $0.25 \mu \mathrm{m}$ film thickness) and data were acquired in electron impact (EI) mode $(45 \mathrm{eV})$. The operating conditions were: injector temperature $300^{\circ} \mathrm{C}$; transfer line temperature $300^{\circ} \mathrm{C}$; oven temperature program $120^{\circ} \mathrm{C}(1 \mathrm{~min}), 20^{\circ} \mathrm{C} \min ^{-1}$ to $150^{\circ} \mathrm{C}, 8 \mathrm{~min}$ at $150{ }^{\circ} \mathrm{C}$, $4{ }^{\circ} \mathrm{C} \mathrm{min}{ }^{-1}$ to $235^{\circ} \mathrm{C}, 10 \mathrm{~min}$ at $235^{\circ} \mathrm{C}, 12^{\circ} \mathrm{C} \mathrm{min}^{-1}$ to $290{ }^{\circ} \mathrm{C}$, $34 \mathrm{~min}$ at $290^{\circ} \mathrm{C}$ (post-run); carrier gas (helium), $1.2 \mathrm{~mL} \mathrm{~min}^{-1}$; injection mode, splitless (split valve open after $1 \mathrm{~min}$ ) with a purge flow of $50 \mathrm{~mL} \mathrm{~min}{ }^{-1}$.

\subsubsection{Quality control}

An intensive control for external contamination was applied by analyzing many field blanks. The sampler was cleaned twice using a filter and $125 \mathrm{~mL}$ of dichloromethane; the dichloromethane col- 
lected in this way constituted the "blank wet deposition", while the two filters represented the "blank wet filters". In the case of dry deposition, the field blanks were obtained in the same way as that described for the wet deposition.

The limits of detections (LOD) were calculated from the average value of the blanks, plus three standard deviations, while the precision was evaluated by four analyses of a water sample spiked with a known quantity of PCBs, PAHs and PBDEs mixture.

The extraction method accuracy was evaluated by comparing the PCBs, PAHs and PBDEs quantity measured instrumentally with the known concentration added to the water sample.

In the case of PBDEs, the LOD values were evaluated for each congener and ranged from $9 \mathrm{pg}$ for PBDE 138 to $1885 \mathrm{pg}$ for PBDE 44. The maximum relative standard deviation (\%) was $12.41 \%$ for PBDE 138 , while in all the other cases, the values were under $8 \%$. The accuracy results showed a systematic negative error that caused an underestimation of the result that was never worse than $-15.8 \%$ (BDE 153), although BDE 47 and 99 had values that did not exceed $-10 \%$.

With regards to the field blanks, the results obtained for the single congeners showed that some values were higher than others. The value obtained for an individual analyte ranged from $3 \pm 0.5 \mathrm{pg}$ (PBDE 138) to $12 \times 10^{2} \pm 1 \times 10^{2} \mathrm{pg}$ (PBDE 47) and represented about the $30 \%$ of the sample result.

The results concerning the PCBs showed LOD values ranging from $1.2 \mathrm{pg}$ for PCB 69 to $580 \mathrm{pg}$ for PCB 93, with a median for all the congeners equal to $8 \mathrm{pg}$. The precision for the different chlorination classes, expressed as the relative standard deviation, was found to be close to $2-5 \%$. The minimum value was $0.5 \%$ for $5-$ $\mathrm{CB}$, while the maximum was $23.1 \%$ for PCB 1 , the lightest. With reference to the accuracy, the greatest error was made in determining the quantity of lighter PCBs, where it was equal to $-22.4 \%$. With regard to the field blanks the value obtained for an individual analyte ranged from $0.3 \pm 0.1 \mathrm{pg}$ (PCB 63) to $46 \pm 7 \mathrm{pg}$ (PCB 149) and represented about the $10 \%$ of the sample value.

Regarding the PAH quality control, LOD values were all under those found in the samples, ranging from $0.7 \mathrm{ng}$ for Benzo(a)anthracene to $18 \mathrm{ng}$ in the case of phenanthrene. An exception was found in the case of some wet deposition samples collected in the period between the 7th of July and 2nd of August. The precision expressed as the relative standard deviation for each congener and calculated on four samples of water after the addition of a known quantity of a single PAH, varied from $1.1 \%$ for Anthracene to $35.8 \%$ for Acenaphthylene. For most of the other PAHs the relative standard deviation did not exceed $15 \%$. The accuracy of the study showed an under estimation equal to $1.3 \%$ of the total quantity of spike added. The values obtained for the field blanks ranged from $0.2 \mathrm{ng}$ for Indeno( $1,2, c-d)$ pyrene to $14.2 \mathrm{ng}$ for Phenanthrene.

\section{Results and discussion}

\subsection{PBDE: wet and dry depositions}

Table 1 shows the mean daily fluxes of PBDE dry deposition during the sampling period. Each PBDE is reported with its IUPAC name and the number of $\mathrm{Br}$ atoms is indicated. It is interesting to note that not all PBDEs contribute in the same way to the mean daily total flux; in particular three of them, 47, 99 and 183 account for $80 \%$ of the entire dry deposition, except in the period from 4 th May to 1st June, when the input was $69 \%$.

In the same way as for the dry depositions, Table 2 shows the flux variations for wet depositions during the period of study, it can be seen that the most abundant compounds are 47, 99 and 183. Their contributions are higher than those observed in the dry deposition, with values ranging from $78 \%$ to $89 \%$.

Fig. 2 reports the comparison between fluxes of the dry and wet depositions collected in the sampling period. It is evident that the flux trends are different in time. In particular, the dry fluxes seem to be constant in time, while the wet fluxes present significant fluctuations, mostly in the March-November period when the minimum flux (1701 $\mathrm{pg} \mathrm{m}^{-2} \mathrm{~d}^{-1}$ ) was 50 times smaller than the maximum (88 $647 \mathrm{pg} \mathrm{m}^{-2} \mathrm{~d}^{-1}$ ). As seen in Fig. 2, the wet deposition shows a relationship with atmospheric precipitation. In fact, it is possible to assume that the removal efficiency of wet deposition is elevated, because of the scavenging effect present in this period. In contrast, the dry deposition fluxes are greatest when the wet deposition reaches a minimum value and precipitations are less abundant.

A comparison between the obtained results and those reported in the literature is difficult, due to the lack of data relative to PBDE concentrations in atmospheric deposition in the Venice Lagoon.

The temporal trend of the single PBDEs, in wet and dry depositions, showed a prevalence of BDEs 47, 99, 100 and 183. This is in accordance with many works reported in the literature (De Wit, 2002; Ter Shure and Larsoon, 2002; Law et al., 2006). In fact, BDEs 47, 99 and 100 are the main constituents of the commercial mixture Penta-BDE widely used in the 1990s. The BDE 183 was employed in another mixture, Octa-BDE, which was especially used in Eastern Europe. In the light of the above data, it is possible to hypothesize that the PBDEs present in the aerosol of Venice Lagoon derive from various commercial mixtures of different origins.

\subsection{PCB: wet and dry depositions}

Table 3 shows the flux variations of PCB dry and wet depositions during the sampling period. Throughout, the study period for the dry deposition, the $\mathrm{PCB}$ class that contributes most to the total flux is that of the ESA-chlorinated compounds, accounting

Table 1

Mean daily fluxes for dry deposition in the different sampling periods.

\begin{tabular}{|c|c|c|c|c|c|c|c|c|}
\hline \multirow[t]{2}{*}{ PBDE } & \multirow[t]{2}{*}{$\mathrm{n} . \mathrm{Br}$} & \multicolumn{7}{|l|}{ Flux $\left(\mathrm{pg} \mathrm{m}^{-2} \mathrm{~d}^{-1}\right)$} \\
\hline & & 15 March-4 May & 4 May-1 June & 1 June-7 July & 7 July-2 August & 2 August-20 September & 20 September-17 October & 17 October-23 November \\
\hline 28 & 3 & 18 & 26 & 13 & 18 & 21 & 28 & 29 \\
\hline 47 & 4 & $14 \times 10^{2}$ & $13 \times 10^{2}$ & $12 \times 10^{2}$ & $19 \times 10^{2}$ & $17 \times 10^{2}$ & $11 \times 10^{2}$ & $26 \times 10^{2}$ \\
\hline 100 & 5 & $29 \times 10^{1}$ & $34 \times 10^{1}$ & $24 \times 10$ & $31 \times 10^{1}$ & $37 \times 10^{1}$ & $19 \times 10^{1}$ & $41 \times 10^{1}$ \\
\hline 99 & 5 & $13 \times 10^{2}$ & $20 \times 10^{2}$ & $11 \times 10^{2}$ & $97 \times 10^{1}$ & $14 \times 10^{2}$ & $19 \times 10^{1}$ & $17 \times 10^{2}$ \\
\hline 85 & 5 & 24 & $41 \times 10^{1}$ & 42 & 27 & 32 & 27 & 52 \\
\hline 154 & 6 & 45 & $33 \times 10^{1}$ & $12 \times 10$ & $22 \times 10^{1}$ & $22 \times 10^{1}$ & $26 \times 10^{1}$ & 42 \\
\hline 153 & 6 & 30 & $30 \times 10^{1}$ & $16 \times 10$ & $12 \times 10^{1}$ & $13 \times 10^{1}$ & $14 \times 10^{1}$ & 54 \\
\hline 138 & 6 & n.d. & 94 & 73 & $10 \times 10^{1}$ & 6 & 12 & 4 \\
\hline 183 & 7 & n.d. & n.d. & $61 \times 10^{1}$ & $10 \times 10^{2}$ & $56 \times 10^{1}$ & $23 \times 10^{2}$ & n.d. \\
\hline \multirow{2}{*}{\multicolumn{2}{|c|}{$\begin{array}{l}\text { Total flux PBDE } \\
\text { \%PBDE: } 47 \text {, } \\
99,183\end{array}$}} & $32 \times 10^{2}$ & $49 \times 10^{2}$ & $35 \times 10^{2}$ & $48 \times 10^{2}$ & $44 \times 10^{2}$ & $42 \times 10^{2}$ & $49 \times 10^{2}$ \\
\hline & & $87 \%$ & $69 \%$ & $82 \%$ & $82 \%$ & $82 \%$ & $84 \%$ & $88 \%$ \\
\hline
\end{tabular}


Table 2

Mean daily fluxes for wet deposition in the different sampling periods.

\begin{tabular}{|c|c|c|c|c|c|c|c|c|}
\hline \multirow[t]{2}{*}{ PBDE } & \multirow[t]{2}{*}{$\mathrm{n} . \mathrm{Br}$} & \multicolumn{7}{|l|}{ Flux $\left(\mathrm{pg} \mathrm{m}^{-2} \mathrm{~d}^{-1}\right)$} \\
\hline & & 15 March-4 May & 4 May-1 June & 1 June-7 July & 7 July-2 August & 2 August-20 September & 20 September-17 October & 17 October-23 November \\
\hline 28 & 3 & 22 & n.d. & 48 & 3 & 205 & 118 & 75 \\
\hline 47 & 4 & $17 \times 10^{2}$ & $13 \times 10^{2}$ & $52 \times 10^{2}$ & $12 \times 10^{2}$ & $43 \times 10^{3}$ & $10 \times 10^{3}$ & $73 \times 10^{2}$ \\
\hline 100 & 5 & $24 \times 10^{1}$ & $24 \times 10^{1}$ & $10 \times 10^{2}$ & $15 \times 10^{1}$ & $67 \times 10^{2}$ & $12 \times 10^{2}$ & $11 \times 10^{2}$ \\
\hline 99 & 5 & $13 \times 10^{2}$ & $10 \times 10^{2}$ & $47 \times 10^{2}$ & $13 \times 10^{1}$ & $27 \times 10^{3}$ & $45 \times 10^{2}$ & $46 \times 10^{2}$ \\
\hline 85 & 5 & 18 & 25 & $11 \times 10^{1}$ & $11 \times 10^{1}$ & $44 \times 10^{1}$ & 91 & 87 \\
\hline 154 & 6 & 60 & 56 & $47 \times 10^{1}$ & 23 & $20 \times 10^{2}$ & $58 \times 10^{1}$ & $18 \times 10^{1}$ \\
\hline 153 & 6 & 46 & 56 & $48 \times 10^{1}$ & 38 & $14 \times 10^{2}$ & $44 \times 10^{1}$ & $16 \times 10^{1}$ \\
\hline 138 & 6 & 4 & 13 & $32 \times 10^{1}$ & 41 & $61 \times 10^{1}$ & $19 \times 10^{1}$ & 18 \\
\hline 183 & 7 & n.d. & n.d. & $21 \times 10^{2}$ & n.d. & $76 \times 10^{2}$ & $69 \times 10^{2}$ & $54 \times 10^{1}$ \\
\hline \multicolumn{2}{|c|}{ Total flux PBDE } & $34 \times 10^{2}$ & $27 \times 10^{2}$ & $14 \times 10^{3}$ & $17 \times 10^{2}$ & $89 \times 10^{3}$ & $24 \times 10^{3}$ & $14 \times 10^{3}$ \\
\hline \multicolumn{2}{|c|}{$\begin{array}{c}\text { \%BDE: } 47, \\
99,183\end{array}$} & $89 \%$ & $86 \%$ & $83 \%$ & $78 \%$ & $87 \%$ & $89 \%$ & $88 \%$ \\
\hline
\end{tabular}

for $25 \%$ of the total flux. The sum of hepta-CB and octa-CB is $23 \%$. These data are confirmed in the literature (Tasdemir et al., 2004).

By contrast, the wet fluxes receive their main contribution from the lighter congeners $(1-2-3 \mathrm{CB})$ throughout the sampling period, with the exception of May and between 12th October and 23rd November.

The wet flux variation is more considerable when compared to that of the dry deposition.

Fig. 3 reports the fluxes of dry and wet deposition, highlighting the differences between them. The data referring to wet deposition shows more temporal variations, compared with those relative to dry depositions. In Fig. 3 it is evident that the mean flux increases with increasing precipitation, while the corresponding dry deposition flux decreases at the same time.

An exception is evident in the data relating to the period between the 20th of September and the 17th of October, when the wet deposition flux was highest $\left(105 \mathrm{ng} \mathrm{m}^{-2} \mathrm{~d}^{-1}\right)$. Considering the average quantity of water in relation to a single event, and not the total quantity of precipitation events, it is possible to see an increase in values during this period. This reflects the presence of storm events, whose intensity probably promoted the scavenging process, increasing the wet depositional flux of PCBs.

In the periods when dry deposition was higher than wet deposition, hepta-CB, hepta/octa-Cb and penta-CB were mostly deposited. Conversely, when wet deposition was more abundant, there was a clear prevalence for PCBs with a low chlorination number. It is likely that the precipitation scavenging effect was more efficient towards the lighter compounds because of their greater solubility in water.

\subsection{PAH: wet and dry depositions}

Table 4 reports the PAH dry and wet fluxes during the sampling period. For both dry and wet depositions it is evident that

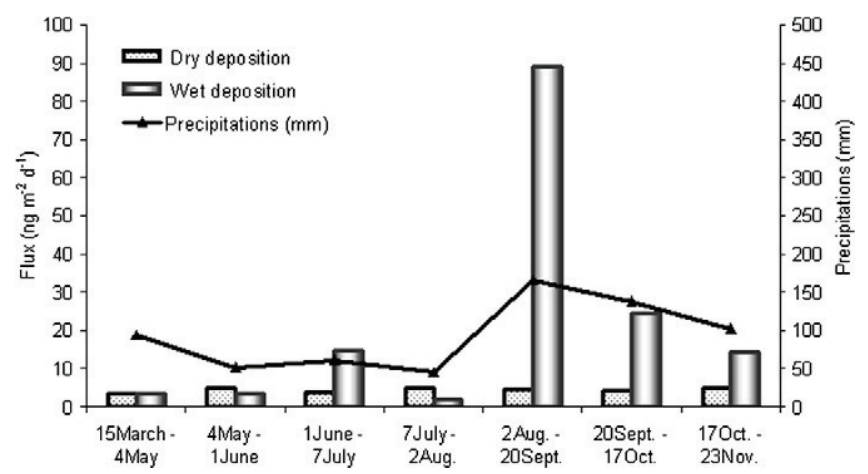

Fig. 2. PBDE wet and dry fluxes.

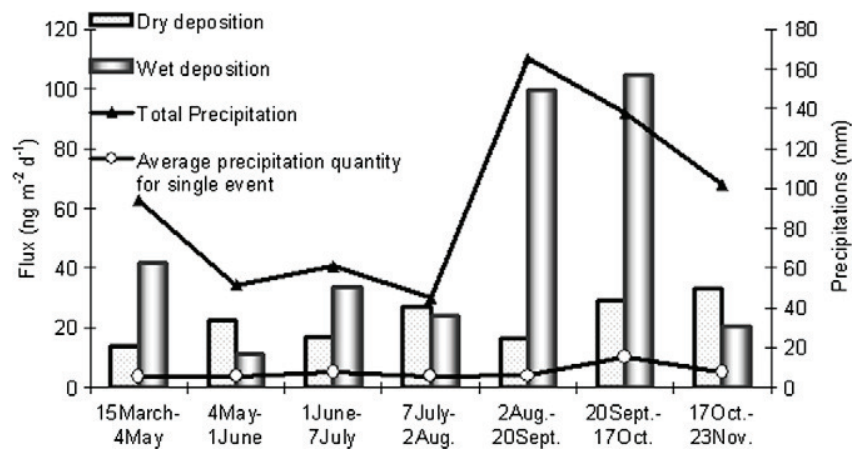

Fig. 3. $P C B$ : fluxes of dry and wet depositions.

Table 3

PCB: fluxes of dry and wet depositions.

\begin{tabular}{|c|c|c|c|c|c|c|}
\hline & \multicolumn{3}{|l|}{ Dry deposition } & \multicolumn{3}{|l|}{ Wet deposition } \\
\hline & $\begin{array}{l}\text { Minimum flux } \\
\left(\mathrm{ng} \mathrm{m}^{-2} \mathrm{~d}^{-1}\right)\end{array}$ & $\begin{array}{l}\text { Maximum flux } \\
\left(\mathrm{ng} \mathrm{m}^{-2} \mathrm{~d}^{-1}\right)\end{array}$ & $\begin{array}{l}\text { Mean flux } \\
\left(\mathrm{ng} \mathrm{m}^{-2} \mathrm{~d}^{-1}\right)\end{array}$ & $\begin{array}{l}\text { Minimum flux } \\
\left(\mathrm{ng} \mathrm{m}^{-2} \mathrm{~d}^{-1}\right)\end{array}$ & $\begin{array}{l}\text { Maximum flux } \\
\left(\mathrm{ng} \mathrm{m}^{-2} \mathrm{~d}^{-1}\right)\end{array}$ & $\begin{array}{l}\text { Mean flux } \\
\left(\mathrm{ng} \mathrm{m}^{-2} \mathrm{~d}^{-1}\right)\end{array}$ \\
\hline$\sum$ Fluxes $1-2-3$ CВ & 1.4 & 4.2 & 3.0 & 1.3 & 42 & 14 \\
\hline$\sum$ Fluxes 4 CB & 1.6 & 4.0 & 2.6 & 1.6 & 24 & 8.2 \\
\hline$\sum$ Fluxes $5 \mathrm{CB}$ & 2.6 & 5.9 & 4.3 & 2.0 & 20 & 8.2 \\
\hline$\sum$ Fluxes 6 CB & 3.9 & 9.2 & 6.4 & 2.4 & 20 & 8.2 \\
\hline$\sum$ Fluxes 7-8 CB & 2.8 & 13 & 5.6 & 1.5 & 10 & 5.0 \\
\hline$\sum$ Fluxes 9-10 CB & 0.21 & 0.93 & 0.57 & 0.22 & 10 & 3.9 \\
\hline
\end{tabular}


Table 4

PAH: dry and wet fluxes.

\begin{tabular}{|c|c|c|c|c|c|c|}
\hline \multirow[t]{2}{*}{ PAH } & \multicolumn{3}{|l|}{ Dry deposition } & \multicolumn{3}{|l|}{ Wet deposition } \\
\hline & $\begin{array}{l}\text { Minimum flux } \\
\left(\mathrm{ng} \mathrm{m}^{-2} \mathrm{~d}^{-1}\right)\end{array}$ & $\begin{array}{l}\text { Maximum flux } \\
\left(\mathrm{ng} \mathrm{m}^{-2} \mathrm{~d}^{-1}\right)\end{array}$ & $\begin{array}{l}\text { Mean flux } \\
\left(\text { ng m }^{-2} \mathrm{~d}^{-1}\right)\end{array}$ & $\begin{array}{l}\text { Minimum flux } \\
\left(\mathrm{ng} \mathrm{m}^{-2} \mathrm{~d}^{-1}\right)\end{array}$ & $\begin{array}{l}\text { Maximum flux } \\
\left(\text { ng m }^{-2} \mathrm{~d}^{-1}\right)\end{array}$ & $\begin{array}{l}\text { Mean flux } \\
\left(\text { ng m }^{-2} \mathrm{~d}^{-1}\right)\end{array}$ \\
\hline Acenaphthylene & 1.2 & 2.8 & 1.6 & n.d. & 11 & 5.7 \\
\hline Acenaphthene & 0.2 & 23 & 10 & 3.2 & 35 & 18 \\
\hline Fluorene & 3.9 & 9.5 & 5.5 & 2.9 & 35 & 14 \\
\hline Phenanthrene & 6.0 & 15 & 8.9 & 8.2 & $10 \times 10^{1}$ & 43 \\
\hline Anthracene & 0.2 & 1.6 & 0.6 & 0.5 & 4.0 & 2.0 \\
\hline Fluoranthene & 2.5 & 12 & 7.7 & 5.5 & 52 & 31 \\
\hline Pyrene & 1.7 & 7.2 & 4.4 & 1.2 & 32 & 21 \\
\hline Benzo(a)anthracene & 0.5 & 2.7 & 1.6 & 2.8 & 18.2 & 8.3 \\
\hline Chrysene & 1.6 & 8.0 & 4.6 & 4.3 & 53 & 22 \\
\hline $\operatorname{Benzo}(b)$ fluoranthene & 3.5 & 29 & 12 & 12 & 58 & 28 \\
\hline Benzo $(k)$ fluoranthene & 2.4 & 9.9 & 6.4 & 3.3 & 53 & 19 \\
\hline Benzo $(a)$ pyrene & 1.2 & 16 & 5.7 & 7.9 & 51 & 28 \\
\hline Indeno $(1,2, c-d)$ pyrene & 1.5 & 25 & 8.3 & 11 & $10 \times 10^{1}$ & 36 \\
\hline Dibenzo( $a, h)$ anthracene & 1.2 & 7.9 & 3.5 & 5.6 & 50 & 18 \\
\hline $\operatorname{Benzo}(g, h, i)$ perylene & 1.2 & 24 & 5.9 & 3.8 & 27 & 13 \\
\hline
\end{tabular}

Anthracene ( $4 \mathrm{ng} \mathrm{m}^{-2} \mathrm{~d}^{-1}$ ), Acenaphthylene (maximum value $11.1 \mathrm{ng} \mathrm{m}^{-2} \mathrm{~d}^{-1}$ ), and $\operatorname{Benzo}(a)$ anthracene (maximum value $18.2 \mathrm{ng} \mathrm{m}^{-2} \mathrm{~d}^{-1}$ ) are the least abundant compounds. The most abundant are Phenanthrene, with a medium value of $43.2 \mathrm{ng}$ $\mathrm{m}^{-2} \mathrm{~d}^{-1}$, and Indeno $(1,2, c-d)$ pyrene, with a medium flux of $36.3 \mathrm{ng} \mathrm{m}^{-2} \mathrm{~d}^{-1}$.

It can be seen that the PAH total wet deposition fluxes may be five times more intense, compared to the respective dry depositions, even if, in particular periods of the year (e.g. between 4th May-1st June and 7th July-2nd August), the wet deposition fluxes can be lower than those of dry depositions.

When comparing between dry and wet PAH deposition fluxes collected during the aerosol sampling, there is evidence that the wet fluxes follow atmospheric precipitations, in particular during the second and third period. The lowest wet deposition values are encountered at a time when precipitations are rare or less intense. In this period, the dry deposition fluxes are higher, in agreement with what is observed for PCBs. It can be noted that the maximum wet flux, during the first period of sampling, is principally due to Indeno $(1,2, c-d)$ pyrene, accounting for $20 \%$ of the total. Instead the fluxes registered at the end of the summer show a clear prevalence for Phenanthrene (over 20\% of the sample between 2nd August and 20th September) and Fluoranthene. The atmospheric precipitations in April were characterized by weaker but longer events, while as stated above for PCBs, at the end of the summer precipitations were mainly in the form of rainstorm events. Because of the scavenging effect present during the latter period, it is possible to suppose that the efficiency of wet removal is greater.

A comparison between the data presented in this work and those reported in the literature shows that the fluxes obtained in this study are easily comparable with those reported in Rossini's publications (Rossini et al., 2005), as far as PAHs are concerned. In particular, the flux relative to the Mazzorbetto zone (333 $\left.\mathrm{ng} \mathrm{m}^{-2} \mathrm{~d}^{-1}\right)$ is lower than those observed at all other stations (EZI, Dogaletto $957 \mathrm{ng} \mathrm{m}^{-2} \mathrm{~d}^{-1}$ and Mestre $624 \mathrm{ng} \mathrm{m}^{-2} \mathrm{~d}^{-1}$ ), and is similar to the fluxes registered in the other lagoon sampling sites like: Industrial Porto (3381 $\mathrm{ng} \mathrm{m}^{-2} \mathrm{~d}^{-1}$ ), Venice City (560 $\mathrm{ng} \mathrm{m}^{-2} \mathrm{~d}^{-1}$ ), Lagoon (385 $\left.\mathrm{ng} \mathrm{m}^{-2} \mathrm{~d}^{-1}\right)$, Lagoon $2\left(447 \mathrm{ng} \mathrm{m}^{-2} \mathrm{~d}^{-1}\right)$, and Lagoon 3 (357 $\left.\mathrm{ng} \mathrm{m}^{-2} \mathrm{~d}^{-1}\right)$.

\section{Conclusions}

The present study has provided the first data relating to organic micropollutant fluxes between the atmosphere and the Venice Lagoon surface, indicating that wet and dry depositions of these substances contribute to a different extent to the total deposition flux. In particular, for all the compound classes, it was observed that the dominant contribution came from wet deposition in comparison to dry deposition.

The fluxes calculated for PBDEs, used as flame retardant in plastic materials in the last 10 years, showed the prevalence of 47,99 , 100 and 183 congeners, both in dry and wet fluxes. The first three are used as tracers in the commercial mixture Penta-BDE, widely used in the 90s, while BDE 183 was employed in another mixture Octa-BDE, whose use is widespread in Eastern Europe and Asia. The dominance of these PBDE congeners simultaneously may point to a co-presence of the two substances in the Venice Lagoon deposition.

With regard to PCBs, the flux of $\sum \mathrm{PCB}$, calculated as the sum of single congener fluxes, obtained over the sampling period of $\mathrm{Au}-$ gust-October for wet deposition is in the same order of magnitude of the diffusive flux at the air-water interface (range 58$195 \mathrm{ng} \mathrm{m}^{-2} \mathrm{~d}^{-1}$ ) reported for the Venice Lagoon (Manodori et al., 2007).

The PAH fluxes obtained in the present study are similar to those obtained in Rossini's studies on the atmospheric bulk deposition to the Venice Lagoon. When hypothesising the origin by evaluating the ratio between Phe/Ant and Fl/Py it is evident that the sources are both pyrolytic and combustion fuels derived.

The proposed research aims of this work are the identification and quantification of the contribution of organic micropollutants (PCBs, PAH, etc.) to the aquatic system and to produce an estimate of fluxes and their balance.

The results from the research presented will contribute to forming the basis of a model aiming at describing the processes responsible for pollutants exchange within the whole ecosystem of the Venice Lagoon.

\section{References}

De Wit, C.A., 2002. An overview of brominated flame retardants in the environment. Chemosphere 46, 583-624.

Gambaro, A., Manodori, L., Moret, I., Capodaglio, G., Cescon, P., 2004. Transport of gas-phase polycyclic aromatic hydrocarbons to the Venice Lagoon. Environ. Sci. Technol. 38, 5357-5364.

Gambaro, A., Manodori, L., Zangrando, R., Cincinelli, A., Capodaglio, G., Cescon, P., 2005. Atmospheric PCB concentration at Terra Nova Bay, Antarctica. Environ. Sci. Technol. 39, 9406-9411.

Law, R., Allchin, C., De Boer, J., Covaci, A., Herzke, D., Lepom, P., Morris, S., Tronczynski, J., De Wit, C.A., 2006. Levels and trends of brominated flame retardants in the European environment. Chemosphere 64, 187-208.

Manodori, L., Gambaro, A., Zangrando, R., Turetta, C., Cescon, P., 2006. Polychlorinated Naphthalenes in the gas-phase of the Venice Lagoon atmosphere. Atmos. Environ. 40, 2020-2029.

Manodori, L., Gambaro, A., Moret, I., Capodaglio, G., Cescon, P., 2007. Air-sea gaseous exchange of $\mathrm{PCB}$ at the Venice Lagoon (Italy). Mar. Pollut. Bull. 54, 1634-1644. 
Odabasi, M., Sofuoglu, A., Vardar, N., Tasdemir, Y., Holsen, T.M., 1999. Measurement of dry deposition and air-water exchange of polycyclic aromatic hydrocarbons with the water surface sampler. Environ. Sci. Technol. 33, 426-434.

Rossini, P., Guerzoni, S., Molinaroli, E., Rampazzo, G., De Lazzari, A., Zancanaro, A. 2005. Atmospheric bulk deposition to the lagoon of Venice. Part I. Fluxes of metals, nutrients and organic contaminants. Environ. Int. 31, 959-974.
Tasdemir, Y., Odabasi, M., Vardar, N., Sosuoglu, A., Mutphy, T.J., Holsen, T.M., 2004 Dry deposition fluxes and velocities of polychlorinated biphenils (PCBs) associated with particles. Atmos. Environ. 38, 2447-2456.

Ter Shure, A.F., Larsoon, P., 2002. Polybrominated diphenil ethers in precipitation in Southern Sweden (Skane Lund). Atmos. Environ. 36, 4015-4022. 